\title{
Liquid Phase Plasma Synthesis of Iron Oxide/Carbon Composite as Dielectric Material for Capacitor
}

\author{
Heon Lee, ${ }^{1}$ Sung Hoon Park, ${ }^{1}$ Sun-Jae Kim, ${ }^{2}$ Young-Kwon Park, ${ }^{3}$ Kay-Hyeok An, ${ }^{4}$ \\ Byung-Joo Kim, ${ }^{4}$ and Sang-Chul Jung ${ }^{1}$ \\ ${ }^{1}$ Department of Environmental Engineering, Sunchon National University, Suncheon 540-742, Republic of Korea \\ ${ }^{2}$ Faculty of Nanotechnology and Advanced Materials Engineering, Sejong University, Seoul 143-747, Republic of Korea \\ ${ }^{3}$ School of Environmental Engineering, University of Seoul, Seoul 130-743, Republic of Korea \\ ${ }^{4}$ Korea Institute of Carbon Convergence Technology, Jeonju 561-844, Republic of Korea
}

Correspondence should be addressed to Sang-Chul Jung; jsc@sunchon.ac.kr

Received 8 February 2014; Accepted 16 June 2014; Published 25 June 2014

Academic Editor: Anukorn Phuruangrat

Copyright (C) 2014 Heon Lee et al. This is an open access article distributed under the Creative Commons Attribution License, which permits unrestricted use, distribution, and reproduction in any medium, provided the original work is properly cited.

\begin{abstract}
Iron oxide/carbon composite was synthesized using a liquid phase plasma process to be used as the electrode of supercapacitor. Spherical iron oxide nanoparticles with the size of $5 \sim 10 \mathrm{~nm}$ were dispersed uniformly on carbon powder surface. The specific capacitance of the composite increased with increasing quantity of iron oxide precipitate on the carbon powder up to a certain quantity. When the quantity of the iron oxide precipitate exceeds the threshold, however, the specific capacitance was rather reduced by the addition of precipitate. The iron oxide/carbon composite containing an optimum quantity ( 0.33 atomic \%) of iron oxide precipitate exhibited the smallest resistance and the largest initial resistance slope.
\end{abstract}

\section{Introduction}

Electrochemical energy storage and conversion devices, for example, fuel cells and supercapacitors, are essential tools, due to their high efficiency and environmental compatibility, to develop alternative energy sources and establish sustainable social energy supply systems. In particular, electrochemical capacitor has recently received significant attention owing to its fast recharge capability, long cycling life, and high power density $[1,2]$.

Electrochemical capacitor, also called supercapacitor, ultracapacitor, and, in certain cases, double-layer capacitor, is an energy storage system similar to a battery. In electrochemical capacitors, charge is stored by means of redox reactions (pseudocapacitance) or in electrode-electrolyte doublelayers. The capacitor performance depends on the electrode material, textural parameters, and the functional groups existing on the electrode surface. Carbonaceous materials, such as amorphous carbon, mesoporous carbon, and carbon nanotube, conducting polymers, and noble- and transitionmetal oxides, such as $\mathrm{RuO}_{2}, \mathrm{IrO}_{2}, \mathrm{NiO}, \mathrm{SnO}_{2}$, and $\mathrm{MnO}_{2}$, have been used as electrode materials [3-7]. Among the various electrode materials used in supercapacitors, carbonbased materials were found attractive because of their high specific surface area, high porosity, and good conductivity. The specific capacitance that can be obtained with carbon electrodes, however, is not very large (typically $100-200 \mathrm{~F} / \mathrm{g}$ ) because of its dependence on the electrical double layer at the interface between electrode and electrolyte and the textural parameters of the electrodes.

Using metal oxides, such as $\mathrm{RuO}_{2}$, is a way of improving specific capacitance because they possess pseudocapacitance generated by the redox reactions occurring on the electrode surface. High price of the $\mathrm{RuO}_{2}$ supercapacitor, however, is hindering its wide application [8]. Recently, metal oxide supported carbon materials, as alternative electrode materials, have been reported $[9,10]$. In particular, iron oxide attracted considerable attention because of its low cost, good electrical conductivity, and environment-friendly properties.

Liquid phase plasma (LPP) is reportedly a useful tool to synthesize nanoparticles on supporting materials [11, 12]. Nanoparticles can be generated rapidly by the LPP method 


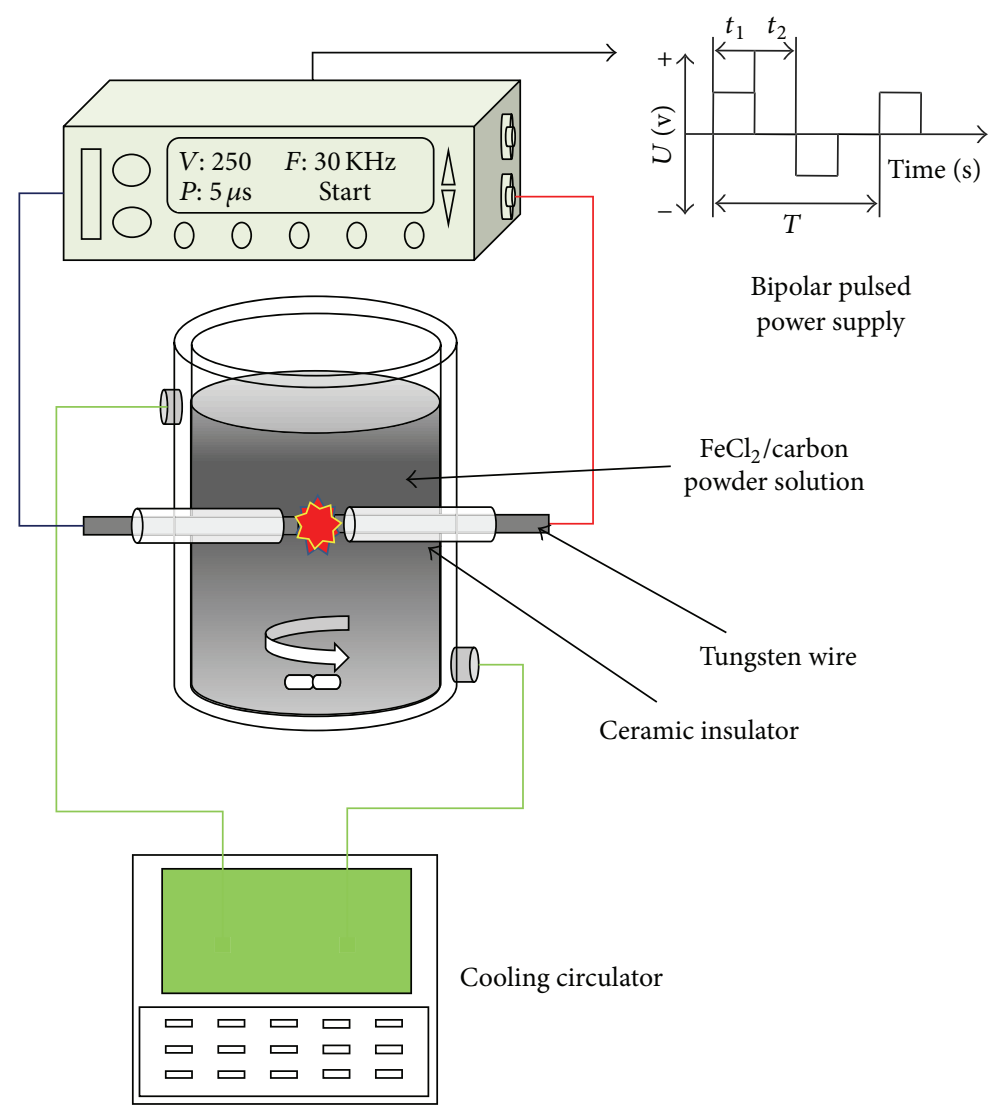

FIGURE 1: Schematic of the experimental system with bipolar pulsed electrical discharge used for synthesis of iron oxide/carbon composite.

without adding reducing agents because plasma provides a reaction field with highly excited energy states [13-15]. In this paper, a new strategy of synthesizing iron oxide/activated carbon composite as dielectric material for capacitor using an LPP reduction system is presented. The effects of plasma discharge conditions are discussed and the resultant products are characterized.

\section{Experimental Procedure}

Activated carbon powder (YP-50F, Koraray Chemical Co. Ltd.) was used as the carbonaceous material in this study. The particle size and specific surface area of this powder were $5 \sim 20 \mu \mathrm{m}$ and $1,500 \sim 1,800 \mathrm{~m}^{2} / \mathrm{g}$, respectively. Iron chloride tetrahydrate $\left(\mathrm{FeCl}_{2} \cdot 4 \mathrm{H}_{2} \mathrm{O}\right.$, Kanto chemical Co., Inc.) was used as the precursor. Iron oxide nanoparticles were generated and precipitated in an aqueous solution using the LPP method. Cetyltrimethylammonium bromide (CTAB, $\mathrm{CH}_{3}\left(\mathrm{CH}_{2}\right)_{15} \mathrm{~N}\left(\mathrm{CH}_{3}\right)_{3} \mathrm{Br}$, Daejung Chemicals \& Metals Co., Ltd) was used as a dispersant. Only reagent-grade chemicals and pure water (Daejung Chemicals \& Metals Co., Ltd) were used in this study.

A schematic diagram of the experimental setup used in this study is shown in Figure 1. Similar apparatus was used in our previous study to generate nanoparticles dispersed in an aqueous solution using the LPP process [16]. Detailed information of the experimental setup can be found in that paper [16].

Pulsed electric discharge was generated by an electrode system in a double annular tube type reactor (ID $50 \mathrm{~mm}$, OD $80 \mathrm{~mm}$, and height $150 \mathrm{~mm}$ ). Cooling water (30\% ethylene glycol, $-5^{\circ} \mathrm{C}$ ) was circulated through the outer channel of the reactor and the cooling circuit. The reactant solution temperature was maintained at $25^{\circ} \mathrm{C}$. A Teflon stirring bar was used in the reactor to maintain the homogeneity of the aqueous solution. The applied voltage, pulse width, and frequency were $250 \mathrm{~V}, 5 \mu \mathrm{s}$, and $30 \mathrm{kHz}$, respectively.

The reactant solution was prepared as follows. CTAB $2 \mathrm{mM}$ was dissolved in $300 \mathrm{~mL}$ of ultrapure water and then $2 \mathrm{~g}$ of YP-50F was added. After stirring, the solution was sonicated for $1 \mathrm{~min}$ for uniform dispersion. Reactant solution was completed by adding $4 \mathrm{mM}$ of iron chloride tetrahydrate to this solution.

Iron oxide/carbon composite was generated by the LPP process. Liquid plasma is defined as a discharge in aqueous solution and stabilized by the exchange of ions and electrons between gas and liquid phases. This plasma generates a number of high active species, for example, hydrogen, oxygen, and hydroxyl radicals, in the aqueous solution. The reactants of the desired reaction are added into the solution and they react with the active species at the interface of gas and liquid phases. The nanoparticle production using the LPP method 


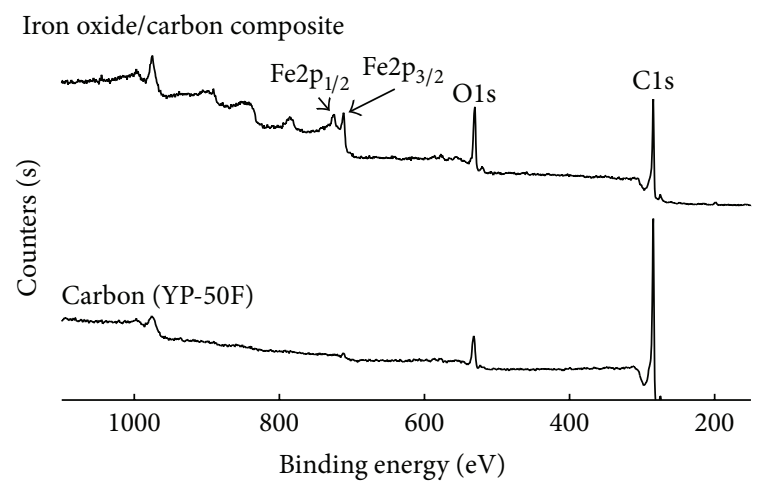

FIGURE 2: XPS full spectrum of iron oxide/carbon composite and carbon powder.

via the reduction of metal ions and hydrogen radicals was found to be an effective process [17].

In this study, different from the previous studies $[16,17]$, the LPP process was operated upon a reactant solution in which the precursor and supporting material were contained together. The nanoparticles generated were to be precipitated on the surface of the supporting material so that the iron oxide/carbon composite is synthesized one step. The composite generated by the LPP process was separated from the solution by 20 min centrifugation, washed with ultrapure water and ethanol, and dried.

The physicochemical properties of the iron oxide/carbon composite synthesized as described above were evaluated using various instruments. The morphology of the composite was observed using a field emission transmission electron microscope (FETEM, TECNAI-20, FEI). X-photoelectron spectroscopy (XPS, Multilab 2000 system, SSK) was used to determine the chemical composition of the composite. The dispersion pattern of the iron oxide particles dispersed on the carbon material was observed using an FESEM (JSM7100F, JEOL). A high resolution FETEM (HR-FETEM, JEM$2100 \mathrm{~F}, \mathrm{JEOL}$ ) was used to analyze the crystal structure of iron oxide. Adsorption-desorption measurements were made using a surface area analyzer (Belsorp mini II, BEL JAPAN, INC.) to obtain the BET surface area and pore volume of the iron oxide/carbon composite.

A coin cell battery was produced to evaluate the electrochemical properties of the composite synthesized. The mass ratio among active carbon (YP-50F), conducting agent, and binder was $8: 1: 1$. Super $P$ conductive carbon black (TIMCAL graphite \& carbon com.) was used as the conducting agent. A mixture of SBR (Styrene-Butadiene Rubber) and CMC (Carboxylmethyl cellulose) was used as the binder. $1 \mathrm{M}$ $\mathrm{KOH}$ solution was used as the electrolyte. $150 \mu \mathrm{m}$ glass felt was used as the separator. The cyclic voltammetry measurement was conducted with the actuation voltage of $0.1 \sim 0.9 \mathrm{~V}$, the current density of $0.001 \mathrm{~A} / \mathrm{cm}^{2}$, and the scan rate of $10 \mathrm{mV} / \mathrm{s}$. Impedance was measured using an alternating-current impedance analyzer within the frequency range of 0.01 300 kHz. Potentiostat (VSP, Princeton Applied Research) was used to measure electrochemical properties.

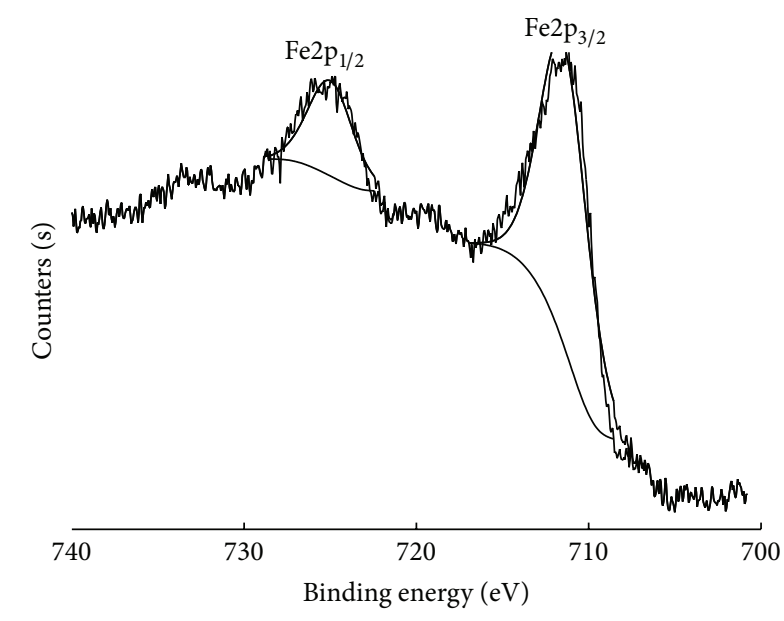

FIGURE 3: Narrow-range XPS spectrum of iron oxide/carbon composite.

\section{Results and Discussion}

3.1. Characteristics of Iron Oxide/Carbon Composites. Full XPS spectrum was first employed to determine the existence of all elements in the iron oxide/carbon composite. Figure 2 shows the XPS spectra of the iron oxide/carbon composite and the carbon powder (YP-50F). C1s and O1s peaks were observed for the carbon powder, whereas Fe2 $\mathrm{p}_{1 / 2}$ and Fe $2 \mathrm{p}_{3 / 2}$ peaks were observed for the precipitated iron oxide. The intensity of the O1s peak was observed to be increased by the doping of iron oxide.

Figure 3 shows the narrow-range XPS spectrum of iron oxide/carbon composite. Fe2 $\mathrm{p}_{1 / 2}$ and $\mathrm{Fe} 2 \mathrm{p}_{3 / 2}$ peaks were observed at the binding energy levels of $725.2 \mathrm{eV}$ and $711.7 \mathrm{eV}$, respectively, indicating that $\mathrm{Fe}$ existed as $\mathrm{FeO}$ and $\mathrm{Fe}_{3} \mathrm{O}_{4}$ $[18,19]$.

Figure 4 shows the FESEM photos of the surface of the composite synthesized with different LPP process times. The dots shown on the carbon powder surface were produced by image-mapping Fe. The number of dots increased with increasing LPP process time, indicating that the amount of iron oxide precipitated increased with increasing LPP process time. In addition, the dispersion of iron oxide nanoparticles on the carbon powder surface was quite good.

The chemical compositions of the iron oxide/carbon composites synthesized with different LPP process times, analyzed using EDX spectrum, are summarized in Table 1. The bare YP-50F consisted of $97.75 \%$ of carbon and $2.25 \%$ of oxygen, in atomic \%. The quantities of oxygen and $\mathrm{Fe}$ in the iron oxide/carbon composite increased with increasing LPP process time, which is in good agreement with the results shown in Figures 3 and 4.

Figure 5 shows the HR-FETEM image of the iron oxide/carbon composite. The average size of iron oxide nanoparticles precipitated on the surface of YP-50F was $5 \sim 10 \mathrm{~nm}$, whereas the lattice fringes of the nanoparticles were approximately $3 \AA$. The ED pattern did not show many spots and circles, indicating that the iron oxide particles precipitated are very fine amorphous particles. 


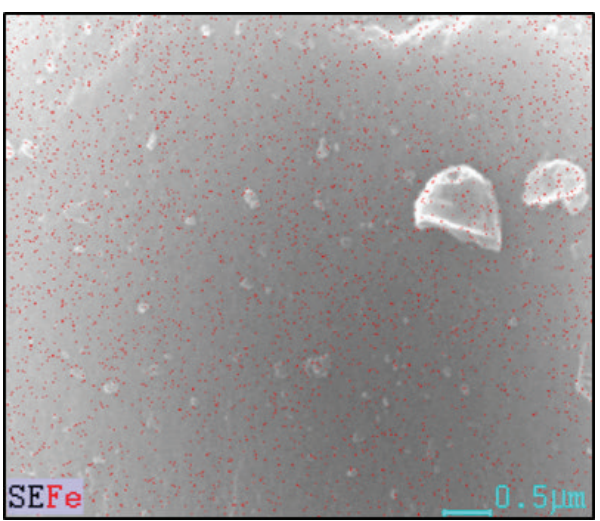

(a)

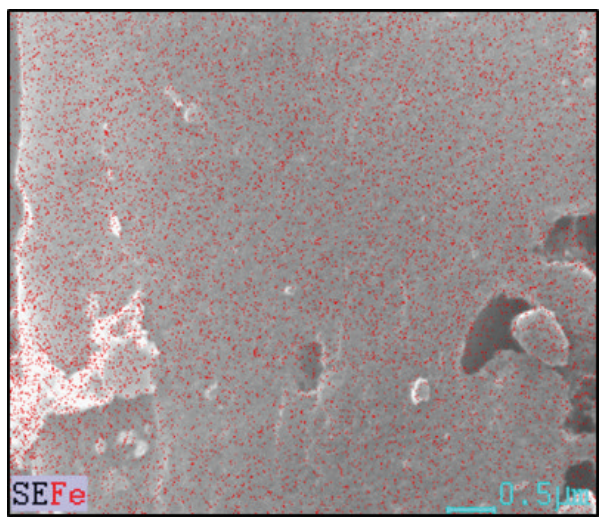

(c)

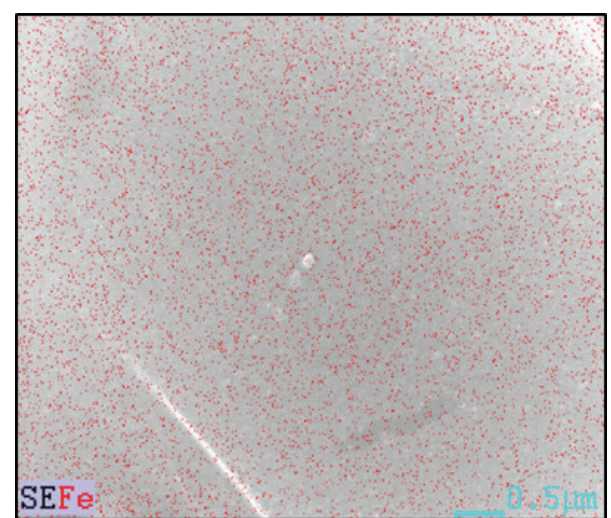

(b)

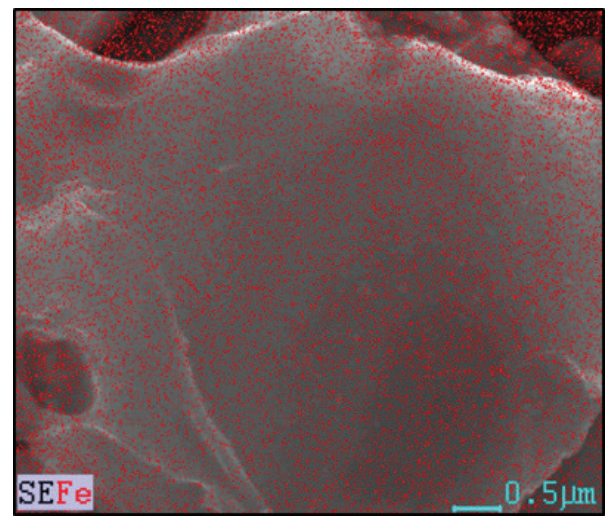

(d)

FIGURE 4: FESEM images of iron oxide particles mapped on composite synthesized with different LPP process times; (a) 15 min, (b) 30 min, (c) $45 \mathrm{~min}$, and (d) $60 \mathrm{~min}$.

TABLE 1: Chemical composition of YP-50F and composites synthesized with different LPP process times.

\begin{tabular}{|c|c|c|c|c|c|c|}
\hline \multirow{2}{*}{ LPP process time } & \multicolumn{2}{|c|}{$\mathrm{C}$} & \multicolumn{2}{|c|}{$\mathrm{O}$} & \multicolumn{2}{|c|}{$\mathrm{Fe}$} \\
\hline & $\mathrm{Wt} \%$ & At $\%$ & Wt \% & At $\%$ & $\mathrm{Wt} \%$ & At $\%$ \\
\hline Bare YP-50F & 97.03 & 97.75 & 2.97 & 2.25 & - & - \\
\hline $15 \mathrm{~min}$ & 95.97 & 97.41 & 3.15 & 2.40 & 0.88 & 0.19 \\
\hline $30 \mathrm{~min}$ & 94.82 & 96.84 & 3.69 & 2.83 & 1.49 & 0.33 \\
\hline $45 \mathrm{~min}$ & 93.41 & 96.28 & 4.08 & 3.16 & 2.51 & 0.56 \\
\hline $60 \mathrm{~min}$ & 92.88 & 96.11 & 4.15 & 3.23 & 2.97 & 0.66 \\
\hline
\end{tabular}

\subsection{Electrochemical Measurements. Figure 6 compares the} current-voltage curves, plotted using the cyclic voltammetry measurement, of iron oxide/carbon composites prepared with different LPP process times. The composite prepared with the plasma process time of 30 min exhibited the largest specific capacitance, followed by that prepared with the process time of $45 \mathrm{~min}$. This result indicates that the precipitation of adequate quantity of iron oxide nanoparticles on the carbon powder matrix improves the performance of the carbon electrode. The composites prepared with the process time of $60 \mathrm{~min}$, however, exhibited a smaller specific capacitance than that of bare YP-50F, suggesting that too large quantity of iron oxide nanoparticle precipitate may backfire. The difference in the physical properties of iron oxide/carbon composite synthesized with different process times was investigated using a surface area analyzer (Table 2). The BET surface area and total pore volume of the composite decreased with increasing LPP process time. Generally, activated carbon has a number of small pores divided, according to their size, into micropores $(<2 \mathrm{~nm})$, mesopores $(2 \sim 50 \mathrm{~nm})$, and macropores $(>50 \mathrm{~nm})$. The specific surface area of iron oxide particle precipitated during the LPP process is smaller than that of activated carbon (YP-50F). Therefore, the reduction in the BET surface area and total pore volume due to LPP process can be attributed to the precipitation of iron oxide particles causing the blocking of pores of YP-50F. Table 2 shows that the specific capacitance of the composite synthesized with an LPP process time of $30 \mathrm{~min}$ was $6.12 \%$ 


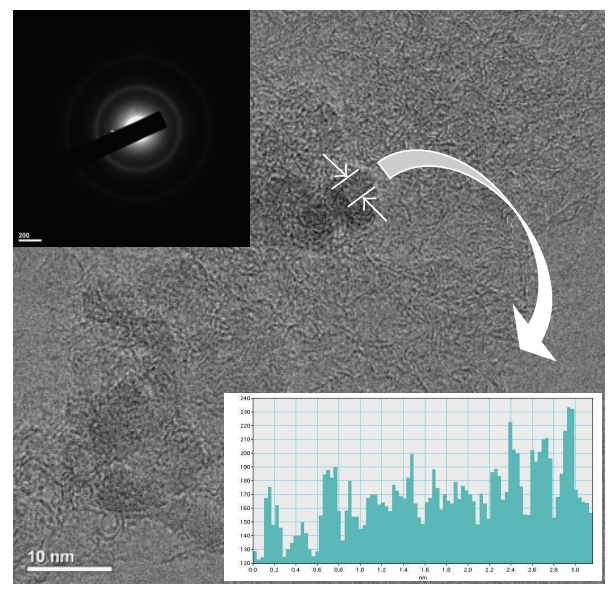

FIGURE 5: HR-FETEM image and corresponding ED pattern of iron oxide nanoparticles on composite prepared by LPP process.

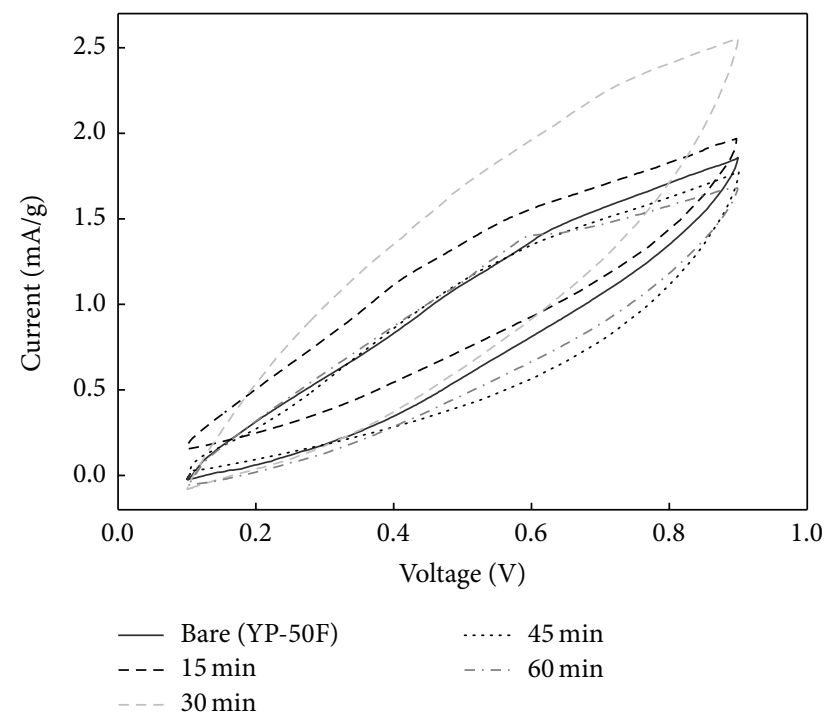

FIGURE 6: Current-voltage curves of iron oxide/carbon composites prepared using LPP method with different process times.

larger than that of bare YP-50F in spite of the reduction in the surface area and pore volume. This result was attributed to the pseudocapacitance generated by the redox reactions of iron oxide particles occurring on the electrode surface. The process time longer than $30 \mathrm{~min}$, however, led to a decrease in the specific capacitance because the effect of reduced surface area became larger than the pseudocapacitance effect.

Figure 6 compares the Nyquist plots, which shows the impedances of the coin cell batteries made of YP-50F or the iron oxide/carbon composites prepared with different LPP process times. Interface resistance, represented by half circle-shaped Nyquist plot, was not exhibited clearly. The composite prepared with $30 \mathrm{~min}$ plasma process time showed the smallest resistance. The composites prepared with $15 \mathrm{~min}$ and $45 \mathrm{~min}$ plasma process times also showed smaller resistance than those of bare YP-50F. The composite prepared with $60 \mathrm{~min}$ plasma process time, however, exhibited a larger

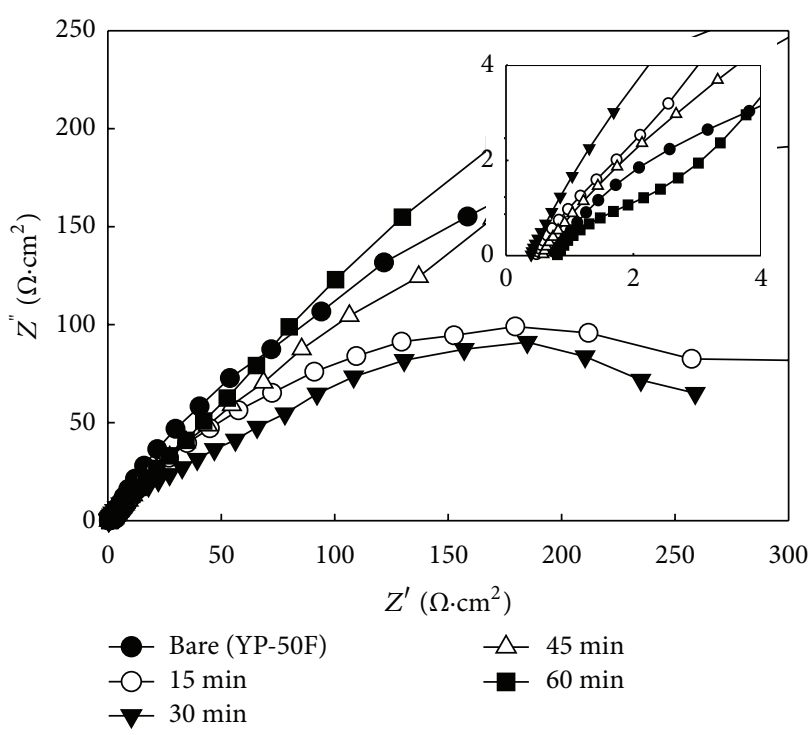

FIGURE 7: Nyquist plots of iron oxide/carbon composites prepared by LPP method with different process times.

TABle 2: Physical properties and specific capacitance of the iron oxide/AC composite synthesized with different LPP process times.

\begin{tabular}{lccc}
\hline $\begin{array}{l}\text { LPP process } \\
\text { time }\end{array}$ & $\begin{array}{c}\text { BET } \\
{\left[\mathrm{m}^{2} / \mathrm{g}\right]}\end{array}$ & $\begin{array}{c}\text { Total pore volume } \\
{\left[\mathrm{cm}^{3} / \mathrm{g}\right]}\end{array}$ & $\begin{array}{c}\text { Specific capacitance } \\
{[\mathrm{F} / \mathrm{g}]}\end{array}$ \\
\hline Bare YP-50F & 1712.6 & 0.8294 & 13.96 \\
$15 \mathrm{~min}$ & 1523.9 & 0.7367 & 13.48 \\
$30 \mathrm{~min}$ & 1488.3 & 0.7191 & 14.87 \\
$45 \mathrm{~min}$ & 1447.5 & 0.6983 & 14.32 \\
$60 \mathrm{~min}$ & 1403.5 & 0.6806 & 12.93 \\
\hline
\end{tabular}

resistance than that of bare YP-50F. The small box included in Figure 7 shows the Warburg impedance (initial resistance slope) measurement results. Generally, large initial resistance slope indicates quick transfer of the ions of the electrolyte inside the pore structure. The composites prepared with 30 min and 60 min plasma process times showed the largest and the smallest initial slopes, respectively.

\section{Conclusions}

Liquid phase plasma process was used, for the first time, to synthesize iron oxide/carbon composite by precipitating iron oxide on carbonaceous material, intended for the application to supercapacitor electrode. Uniform dispersion of $5 \sim 10 \mathrm{~nm}$ sized spherical iron oxide nanoparticles on the carbon powder surface was obtained. The quantity of iron oxide nanoparticle precipitate increased with increasing LPP process time. Increase in the quantity of iron oxide precipitate up to 0.33 atomic \% resulted in the increase in the specific capacitance. When the quantity of iron oxide precipitate is too large, however, capacitance decreased with increasing iron oxide quantity. The iron oxide/carbon composite with the optimal quantity ( 0.33 atomic $\%$ ) of iron oxide precipitate exhibited the smallest resistance and the largest initial resistance slope. 


\section{Conflict of Interests}

The authors declare that there is no conflict of interests regarding the publication of this paper.

\section{Acknowledgment}

This study was supported by a Grant from the Carbon Valley R\&D Project (Project no. R0002651) funded by the Ministry of Trade, Industry, and Energy (MOTIE), Republic of Korea.

\section{References}

[1] B. E. Conway, "Transition from "supercapacitor" to "battery" behavior in electrochemical energy storage," Journal of the Electrochemical Society, vol. 138, no. 6, pp. 1539-1548, 1991.

[2] J. R. Miller and P. Simon, "Electrochemical capacitors for energy management," Science, vol. 321, no. 5889, pp. 651-652, 2008.

[3] E. Frackowiak and F. Béguin, "Carbon materials for the electrochemical storage of energy in capacitors," Carbon, vol. 39, no. 6, pp. 937-950, 2001.

[4] F. Bonhomme, J. C. Lassègues, and L. Servant, "Raman spectroelectrochemistry of a carbon supercapacitor," Journal of the Electrochemical Society, vol. 148, no. 11, pp. E450-E458, 2001.

[5] K. C. Liu and M. A. Anderson, "Porous nickel oxide/nickel films for electrochemical capacitors," Journal of the Electrochemical Society, vol. 143, no. 1, pp. 124-130, 1996.

[6] B. E. Conway, V. Birss, and J. Wojtowicz, "The role and utilization of pseudocapacitance for energy storage by supercapacitors," Journal of Power Sources, vol. 66, no. 1-2, pp. 1-14, 1997.

[7] Y. S. Yoon, W. I. Cho, J. H. Lim, and D. J. Choi, "Solid-state thinfilm supercapacitor with ruthenium oxide and solid electrolyte thin films," Journal of Power Sources, vol. 101, no. 1, pp. 126-129, 2001.

[8] J. P. Zheng, P. J. Cygan, and T. R. Jow, "Hydrous ruthenium oxide as an electrode material for electrochemical capacitors," Journal of the Electrochemical Society, vol. 142, no. 8, pp. 2699-2703, 1995.

[9] H. Huwe and M. Fröba, "Synthesis and characterization of transition metal and metal oxide nanoparticles inside mesoporous carbon CMK-3," Carbon, vol. 45, no. 2, pp. 304-314, 2007.

[10] N. A. Fellenz, S. G. Marchetti, J. F. Bengoa, R. C. Mercader, and S. J. Stewart, "Synthesis and magnetic characterization of magnetite particles embedded in mesoporous MCM-41," Journal of Magnetism and Magnetic Materials, vol. 306, no. 1, pp. 30-34, 2006.

[11] P. Pootawang, N. Saito, O. Takai, and S. Y. Lee, "Rapid synthesis of ordered hexagonal mesoporous silica and their incorporation with Ag nanoparticles by solution plasma," Materials Research Bulletin, vol. 47, no. 10, pp. 2726-2729, 2012.

[12] X. Hu, X. Shen, O. Takai, and N. Saito, "Facile fabrication of PtAu alloy clusters using solution plasma sputtering and their electrocatalytic activity," Journal of Alloys and Compounds, vol. 552, pp. 351-355, 2013.

[13] J. K. Lung, J. C. Huang, D. C. Tien et al., "Preparation of gold nanoparticles by arc discharge in water," Journal of Alloys and Compounds, vol. 434-435, pp. 655-658, 2007.

[14] O. Takai, "Solution plasma processing," Pure and Applied Chemistry, vol. 80, no. 9, pp. 2003-2011, 2008.
[15] N. Saito, J. Hieda, and O. Takai, "Synthesis process of gold nanoparticles in solution plasma," Thin Solid Films, vol. 518, no. 3, pp. 912-917, 2009.

[16] H. Lee, S. H. Park, S.-C. Jung, J.-J. Yun, S.-J. Kim, and D.-H. Kim, "Preparation of nonaggregated silver nanoparticles by the liquid phase plasma reduction method," Journal of Materials Research, vol. 28, no. 8, pp. 1105-1110, 2013.

[17] J. Hieda, N. Saito, and O. Takai, "Exotic shapes of gold nanoparticles synthesized using plasma in aqueous solution," Journal of Vacuum Science and Technology A: Vacuum, Surfaces and Films, vol. 26, no. 4, pp. 854-856, 2008.

[18] J. Guo, L. Zhang, A. Xian, and J. K. Shang, "Solderability of electrodeposited Fe-Ni alloys with eutectic SnAgCu solder," Journal of Materials Science and Technology, vol. 23, no. 6, pp. 811-816, 2007.

[19] N. Li, G. W. Huang, X. J. Shen, H. M. Xiao, and S. Y. Fu, "Controllable fabrication and magnetic-field assisted alignment of $\mathrm{Fe}_{3} \mathrm{O}_{4}$-coated $\mathrm{Ag}$ nanowires via a facile co-precipitation method," Journal of Materials Chemistry C, vol. 1, no. 32, pp. 4879-4884, 2013. 

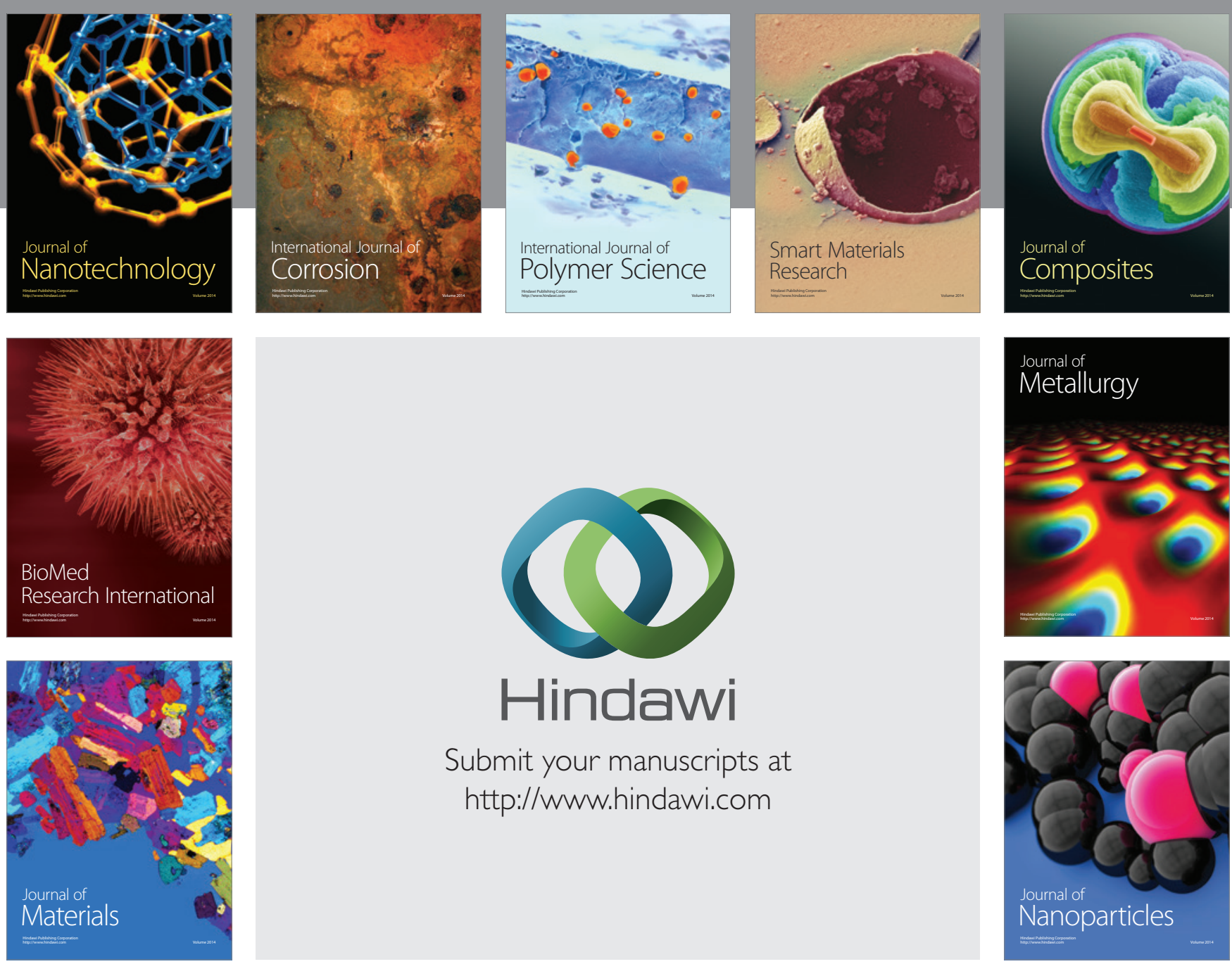

Submit your manuscripts at http://www.hindawi.com
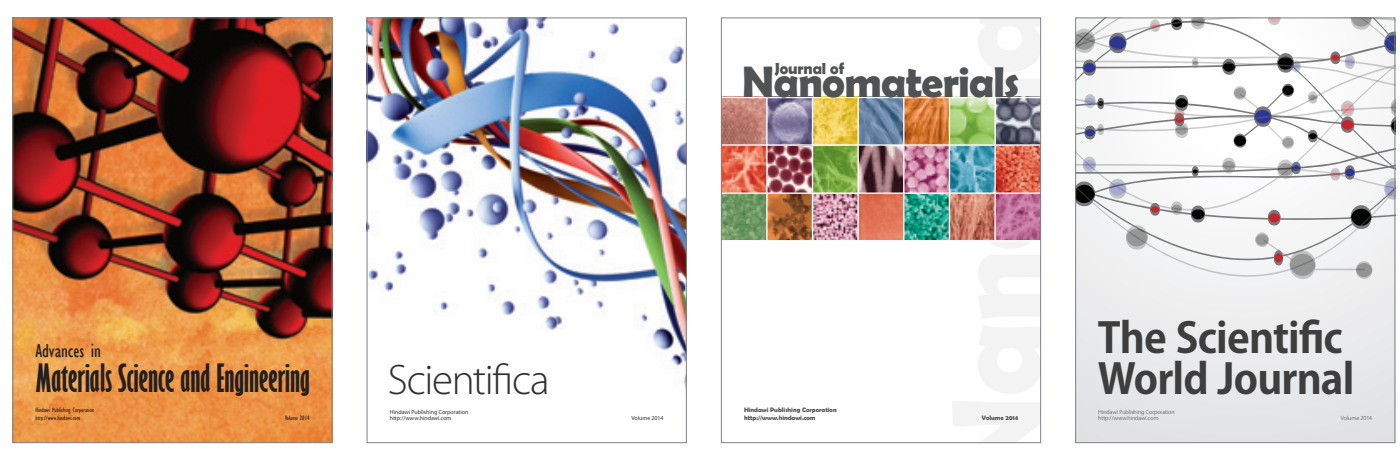

\section{The Scientific World Journal}
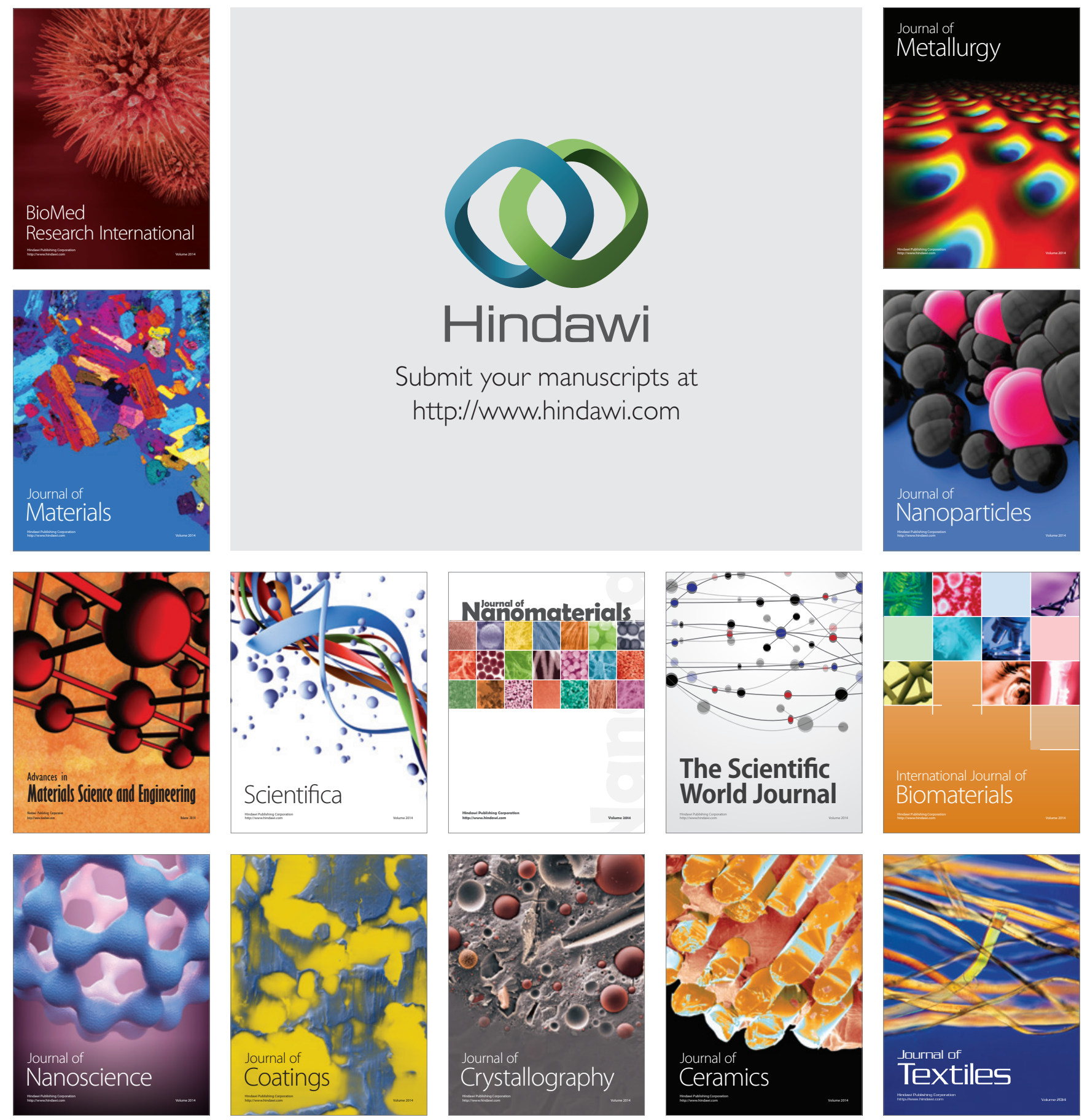